BY W. B, CRAMER.

Chloracet-m-nitroanilide, $\mathrm{ClCH}_{2} \mathrm{CONHC}_{6} \mathrm{H}_{4} \mathrm{NO}_{2}$. - This anilide was prepared from chloracetyl chloride and $m$-nitroaniline. It crystallized from alcohol in plates and melted at $\operatorname{IOI}^{\circ}-102^{\circ} \mathrm{C}$. A nitrogen determination gave:

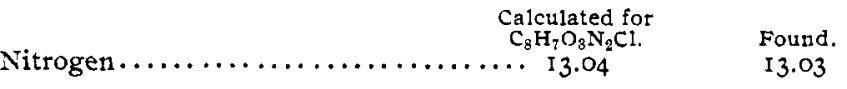

Labile $m$-Nitrophenylpseudothiohydantoin.-This body was obtained by boiling in benzene chloracet- $m$-nitroanilide with potassium thiocyanate for twenty minutes. It crystallized from alcohol in the form of plates and melted at $183^{\circ}-184^{\circ} \mathrm{C}$. A nitrogen determination gave:

Nitrogen ........................

Action of Alkali.-This hydantoin melting at $183^{\circ}-184^{\circ}$ dissolved in cold sodium hydroxide solution. On neutralizing with acetic acid a mass of needles separated. They were purified by crystallizing from benzene and melted at $133^{\circ}-134^{\circ} \mathrm{C}$. A nitrogen determination agreed with the calculated for m-nitrophenylcyanamide.

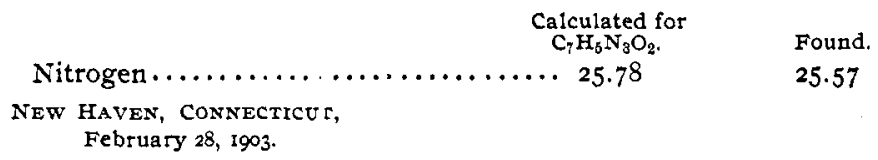

[CONTRIBUTION FROM THE CHEMICAL LABORATORY OF THE NORTH Carolina DEPaRTMENT OF AGRICULTURE.]

\title{
METHODS FOR THE DETERMINATION OF TOTAL PHOS- PHORIC ACID AND POTASH IN SOILS.
}

\author{
BY C. B. WILLTAMS.
}

Received Februaty 9, 9903 .

AGRICULTURAL chemists have seemingly, in recent years, placed too little stress upon the determination of total plant food in soils, as a knowledge of the quantity present is necessary for a thorough understanding of the potentialities, culture methods, and fertilizer requirements of any soil, as well as entering vitally into the interpretations given availability results. With these facts in mind, the writer has, during the past summer, devoted some time to 
modifying well-known analytical methods to a reasonably rapid basis for the determination of total phosphoric acid and potash in soils.

S'IUDY OF DIFFERENT SOLVYNTS FOR PHOSPHORIC ACID.

The results of work with the action of different solvents on phosphoric acid are incorporated in Table I, and it will be seen

TABLE I.-COMParison OF METhODS HOR EFFECTING SOI,UTiON OF SOIL Phosphoric ACID When IO GraMs SOIL, are EMployed.

\begin{tabular}{|c|c|c|c|c|c|c|c|}
\hline \multirow{2}{*}{\multicolumn{2}{|c|}{$\begin{array}{l}\text { Treated } \\
\text { three times } \\
\text { with } \mathrm{HF} \\
\text { and then } \\
\text { fused with } \\
\text { Io grams } \\
\mathrm{Na}_{2} \mathrm{CO}_{3}-\end{array}$}} & \multirow{2}{*}{\multicolumn{2}{|c|}{$\begin{array}{l}\text { Heated on water-bath } \\
\text { for } 11 / 2 \text { hours. }\end{array}$}} & \multicolumn{4}{|c|}{ Digested in Kjeldahl flask I i 2 hours. } \\
\hline & & & & \multirow{2}{*}{$\begin{array}{l}\text { With } \\
50 \mathrm{cc} \text {. } \\
\mathrm{HCl}+ \\
20 \mathrm{cc} \\
\text { HNO.3. } \\
\text { Per cent. } \\
\text { P.O. }\end{array}$} & \multirow{2}{*}{$\begin{array}{c}\text { With } \\
50 \mathrm{cc} \\
\mathrm{HCl} \text { Per } \\
\text { cent. } \\
\mathrm{P}_{2} \mathrm{O}_{0,} .\end{array}$} & \multirow{2}{*}{$\begin{array}{l}\text { With } 50 \mathrm{cc} \\
\text { HCl fol- } \\
\text { lowed by } \\
\text { digestion } \\
\text { 1 hr with } \\
\text { locc. HNO } \\
\text { Per cent. } \\
\text { P.O. }\end{array}$} & \multirow{2}{*}{ 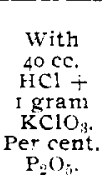 } \\
\hline $\begin{array}{l}\text { Soi1. } \\
\text { No. }\end{array}$ & $\begin{array}{c}\mathrm{Na}_{2} \mathrm{CO}_{3} \\
\mathrm{~K}_{2} \mathrm{CO}_{3} \text { Per } \\
\text { cent. } \mathrm{P}_{2} \mathrm{O}_{5} .\end{array}$ & $\begin{array}{l}\text { With } 30 \mathrm{cc} . \\
\mathrm{HCl} \text {. } \mathrm{Pet} \\
\text { cent. } \mathrm{P}_{2} \mathrm{O}_{5} .\end{array}$ & $\begin{array}{l}\text { With } 30 \mathrm{cc} \text {. } \\
\mathrm{HNO}_{3} . \mathrm{Per} \\
\text { cent. } \mathrm{P}_{2} \mathrm{O}_{5} \text {. }\end{array}$ & & & & \\
\hline \multirow{2}{*}{ I } & \multirow{2}{*}{0.0330} & 0.017 & 0.016 & $\ldots$ & 0.017 & 0.017 & $\cdots$ \\
\hline & & 0.017 & 0.015 & $\ldots$ & $\ldots$ & $\ldots$ & $\ldots$ \\
\hline \multirow[t]{2}{*}{2} & \multirow{2}{*}{0.0292} & 0.017 & 0.014 & 0.017 & 0.016 & 0.015 & 0.016 \\
\hline & & 0.015 & 0.014 & 0.017 & $\cdots$ & $\cdots$ & 0017 \\
\hline \multirow{2}{*}{3} & \multirow{2}{*}{$0.02 \mathrm{I} 2$} & 0.016 & 0.014 & 0.013 & 0.015 & 0.015 & 0.014 \\
\hline & & 0.015 & 0.014 & $\ldots$ & $\ldots$ & $\ldots$ & 0.012 \\
\hline
\end{tabular}

that the results obtained by the last six modes of treatment are practically identical, and uniformly low, while those by the hydrofluoric acid-fusion method, ${ }^{1}$ are perceptibly higher. Fusion of the residues from treatment by the last six methods invariably gave a slight test for phosphoric acid, while, of course, this was not true of the first method, as the residues were entirely decomposed by fusion with sodium and potassium carbonates.? The soils were ignited before treatment by the first four methods, but not with the last three.

As the hydrofluoric acid-fusion method gave results uniformly higher, and representing, we think, all the phosphoric acid in the soil, it has been adopted for the determination of total phosphoric acid in soil survey work in North Carolina. It might be objected that higher results by this method are due to the possible presence of ammonium silicomolybdate, as in the dehydration of silica from the fusion with sodium and potassium carbonates there was only one evaporation to dryness; but this would seem unfounded, as

'Vide Fresenius, "Quantitative Analysis," pp. 424-426.

2 Ibid, pp. 422-424. 
silica gives no reaction in the cold, ${ }^{1}$ and only a strong yellow coloration upon heating.

DE'TERMINATION OF PHOSPHORIC ACID VOLUMETRICALLY VERSUS

GRAVIMETRICALLY.

The volumetric method used is described in this Journal, 23, $8-12,{ }^{2}$ while the gravimetric one employed is the regular official method of the Association of Official Agricultural Chemists. For a test of the relative merits of these two methods of estimating phosphoric acid in soils, where the quantity usually is less than 0.1 per cent., twelve soils (Nos. 23-24) were employed, using solutions obtained by digestion in the water-bath for ten hours with I.I I5 sp. gr. hydrochloric acid, shaking thoroughly each hour. The quantity was determined separately in each twelve original and duplicate soils, the total amount from the twelve originals being 0.0260 , and from duplicates 0.0280 gram. When the totals of the originals and duplicates were dissolved separately with hydrochloric acid, and redetermined by precipitation with magnesia mixture 0.0199 gram phosphoric acid for originals and 0.0198 for duplicates were obtained.

Results on the same twelve soils by the volumetric method, making determinations separately and adding, gave originals 0.02 IO gram phosphoric acid and duplicates 0.0193 gram, which are very close to the composite original and duplicate gravimetric results.

In the light of these results, the volumetric method is considered by far the most accurate for soil work where the percentages of phosphoric acid are usually very low.

\section{SOLUTION OF POTASH IN SOILS.}

Results in Table II on soils Nos. I, 2, and 3 indicate that after ignition and evaporation with hydrofluoric acid five times it is unnecessary to fuse with sodium carbonate, as all potash-bearing silicates have been decomposed, leaving the potash in a form that is easily dissolved by the treatment subsequently given it in the method described elsewhere in this paper.

1 Fresenius' "Qualitative Analysis," p. 332. F. P. Veitch states, however, that silicic acid gives a yellow coloration in the cold (private communication).

2 Vade this Journal, 15, $382 ; J$. Frank. Inst., 136, 362 ; U. S. Dept. of Agriculture, Div. of Chem., Bul1. 43, pp. 68-97; Ibid., Bull. 47, pp. 62-82; /bid.. 49, pp. 60-77; Ibid., 51, pp. 47-56; Ibid., Bull. 56, pp. 36-48;/6rd., Bull. 62, pp. 35-4I; Ibid., Bull. 56, pp. 36-48; Ibid., Bull. 67, pp. 22-26. 


\section{TABI,E II.}

$\begin{array}{ccc}\text { Soil. No. } & \begin{array}{c}\text { Treated five times with } \mathrm{HF} \text {. } \\ \text { Per cent. } \mathrm{K}_{2} \mathrm{O} .\end{array} & \begin{array}{c}\text { Treated five times with } \mathrm{HF}, \\ \text { followed by fusion with } \\ \mathrm{Na}_{2} \mathrm{CO}_{3} \text { Per cent. } \mathrm{X}_{2} \mathrm{O} .\end{array} \\ 0.204 & 0.216 \\ 0.242 & 0.242 \\ 0.232 & 0.232 \\ 0.187 & \left\{\begin{array}{c}0.190 \\ 0.180\end{array}\right.\end{array}$

It might be said here that the reason for using the first evaporation with sulphuric acid in the potash method is that a preliminary test upon soils Nos. 6, II, I3, I5, and I6 worked in duplicate indicated that there was a slight loss in potash if the soils were not saturated with this acid before ignition; the loss probably occurs principally from the volatilization of patash in organic combination.

\section{MOORE'S METHOD. ${ }^{1}$}

With reference to the method of Moore for the determination of total potash in soils I found that as long as the combined amount of iron and alumina remained as low as 2 or 3 per cent., it works very well, although in my hands giving slightly low results, but when from 8 to 12 per cent. of iron and alumina are present, trouble comes from caking upon evaporation to a pasty constituency with platinic chloride, the cake not being dissolved by Moore's acid alcohol, even after standing two or three days.

METHOD FOR THE DETERMINATION OF TOTAI PHOSPHORIC ACID

IN SOILS.

Five grams of soil prepared by passing through a sieve with apertures $0.5 \mathrm{~mm}$. in diameter are placed in a platinum dish and ignited until organic matter has been destroyed; then treated three times with hydrofuoric acid, evaporating to dryness each time on a water-bath, using a platinum rod to stir upon each addition of acid. The residue thus obtained is mixed with 10 grams of a mixture of equal parts of sodium and potassium carbonates, and reduced in an agate mortar to a fine powder, after which it is heated over a blast-lamp, gently at first, until the mass has completely agglutinated, when stronger heat is turned on and continued until calm fusion is attained. Then cool and place the dish and its contents in a beaker, and add sufficient ( $I: I$ ) hydrochloric acid to cover the dish. Place on a water-bath and digest

1 U. S. Department of Agriculture, Isureau of Chemistry, Circular 9, pp. 5-7. 
until the mass has thoroughly loosened from the dish, after which it is removed. Evaporate to dryness on a water-bath and thoroughly dehydrate the silica present by finishing the heating in an air-bath at $110^{\circ} \mathrm{C}$. for four or five hours. Take up with dilute hydrochloric acid and digest on water-bath for twenty to thirty minutes, after which filter from silica, washing the same thoroughly to remove last traces of phosphoric acid. To the filtrate is added sufficient nitric acid to liberate all hydrochloric acid, and the solution is evaporated to a volume of about $40 \mathrm{cc}$. Then neutralize the excess of nitric acid with ammonia, and add Io to I2 grams of ammonium nitrate. After cooling, $30 \mathrm{cc}$. of recently filtered molybdic solution are added and the phosphoric acid precipitated by shaking in a Wagner machine, and determined volumetrically. ${ }^{1}$

METHOD FOR THE DETERMINATION OF TOTAL POTASH IN SOILS.

After saturating 4 grams of soil in a platinum dish thoroughly with dilute (I:I) sulphuric acid, dispel the excess of acid, by gentle heat over a low flame, exercising care that no loss occurs from spurting. Next treat with 2 to $3 \mathrm{cc}$. hydrofluoric acid (free from potash) five times, using a platinum rod to stir occasionally, and evaporate each time to apparent dryness on a water-bath, but just before going to dryness the last time I cc. dilute sulphuric acid is added and the heating continued until practically all hydrofluoric acid and water have been driven off. The dish is then heated over a small flame until the evolution of stlphur trioxide ceases. When this is finished, about $20 \mathrm{cc}$. distilled water, slightly acidified with hydrochloric acid, is added, and digested on a water-bath, stirring accasionally until the liquid has been reduced to about one-third of its original volume. By this time complete solution of the potash has been effected, and the whole contents of the dish are transferred with water to a $200 \mathrm{cc}$. graduated flask, which is afterwards heated on a water-bath to near boiling, when ammonia and ammonium oxalate are added in sufficient quantities to precipitate all iron, alumina and calcium present ( $2 \mathrm{cc}$. have been found sufficient). Allow the solution to cool, shaking two or three times during cooling to reduce the error of occlusion as much as possible. The volume is then made to $200 \mathrm{cc}$., and an aliquot portion correspond-

1 This Journal, 23, 8-12. 
ing to 2 grams of soil is filtered off into a porcelain dish and evaporated to semi-clryness on a water-bath, finishing by heating cautiously over a gentle flame, being careful that loss occurs neither from creeping nor clecrepitation. When dry, ignite gently to decompose oxalates and expel ammonium salts. Take up with Io to $15 \mathrm{cc}$. of hot distilled water, aciclify with 3 or 4 drops of hydrochloric acid, and filter. Determine the potash in the filtrate by precipitation with chloroplatinic acid, etc., as directed in the regular Lindo-Gladding method.

[CONTRIBUTION FROM THE UNIVERSITY OF ILIINOIS, AGRICLLTURAI. EXPERIMENT STATION, No. 9.]

\title{
IMPROVED METHOD FOR SEPARATION AND DETERMII- NATION OF TOTAL ALKALIES IN SOILS.
}

\author{
BY I. H. PETTit. \\ Received February 13. 1903.
}

WHILE: working upon soils in this laboratory, considerable difficulty was found in the determination of the total alkalies. The method used was that outlined in the "Methods of Analysis of the Association of Official Agricultural Chemists." By this method the iron, aluminum, phosphorus, and magnesium are removed from the hydrochloric acid solution by precipitating with barium hydroxide. From the filtrate, barium and calcium are precipitated by ammonium hydroxide and ammonium carbonate. This filtrate is evaporated to dryness, the ammonium salts driven off, and the residue taken up with a little hot water. Ammonium carbonate is again added to remove the last traces of barium, the solution filtered, the filtrate evaporated to dryness in platinum dishes, and the chlorides of the alkalies ignited.

It was found, however, that considerable barium carbonate remained with the ignited alkalies. This appeared as a thin white layer in the bottom of the platinum dishes, when hot water was added. Also, by the addition of ammonium carbonate to this more concentrated solution, more barium was precipitated. This process of precipitation, filtration, and evaporation was necessarily repeated five or six times before a constant weight of chlorides was obtained. Further, it was found that in this solution, in which ammonium carbonate finally gave no precipitate, the addition of a solution of ammonium sulphate gave a precipitate of 